\title{
Serviço Social e Poder Judiciário: aproximações com uma agenda de educação permanente
}

\author{
Social Service and Judicial Power: \\ approaches to a permanent education agenda
}

\author{
Mariana Pires Borba ${ }^{a}$ \\ (D) http://orcid.org/0000-0002-1151-7799 \\ Rosa Maria Castilhos Fernandes ${ }^{b}$ \\ (D) http://orcid.org/0000-0001-5499-714X
}

Resumo: 0 texto socializa reflexões sobre o trabalho profissional junto as necessidades sociais judicializadas que requerem dos assistentes sociais no Poder Judiciário um conjunto de conhecimentos e competências. A Educação Permanente surge como proposta pedagógica de formação dos trabalhadores com função mediadora capaz de propor respostas competentes às exigências éticas e políticas da profissão. A construção coletiva de uma agenda de educação permanente é um desafio para os assistentes sociais.

Palavras-chave: Serviço Social. Poder Judiciário. Educação permanente.

\begin{abstract}
The text shares reflections about the professional work with the judicialized social needs and that require the social workers in the Judiciary Power a set of knowledge and skills. Permanent Education emerges as a pedagogical proposal for the training of workers and has a mediating function capable of proposing competent answers to the ethical and political demands of the profession. The collective construction of a permanent education agenda has become a challenge for social workers.
\end{abstract}

Keywords: Social Service. Judicial power. Permanent education. 


\section{Introdução}

V ivemos tempos de corrosão dos direitos sociais sob comando das forças de mercado demarcadas pelos ditames neoliberais e que, por meio das ações governamentais e políticas, vêm definindo novos arranjos no âmbito das políticas sociais e, concomitantemente, desprezando as desigualdades sociais estruturais que caracterizam a sociedade brasileira. São processos que ameaçam também as estruturas democráticas, a organização popular e que fomentam novas faces à exclusão social, atingindo significativa parcela da população. Impactos sociais, políticos, ambientais e culturais que acirram no cenário brasileiro as disputas e a necessária busca pela justiça social, uma condição para a sobrevivência da classe trabalhadora no seio da luta de classes.

Assim, entendendo o Serviço Social como partícipe das respostas que o Estado e a sociedade têm que dar aos antagonismos de classe, como o referenciado por Iamamoto (2015), iniciamos essas reflexões introdutórias reconhecendo que o Serviço Social se inscreve na dinâmica contraditória de interesses e projetos societários em disputa nos seus espaços ocupacionais, com suas particularidades, mas, fundamentalmente, trata-se de uma profissão comprometida com um projeto ético-político. A essência de tal projeto tem como princípio uma perspectiva crítica da realidade e como propósito contribuir para a superação da ordem social vigente de uma sociedade capitalista que mantém sua lógica de produção e reprodução do capital atingindo as condições de vida da classe trabalhadora (CFESS, 1993).

É no campo sociojurídico que o fenômeno da judicialização dos conflitos e dos direitos sociais se manifesta e os desafios postos à profissão nos mobilizam para a reflexão que propomos neste artigo. A natureza jurídica da aplicação da lei, assim como a ética e a política do trabalho do assistente social tem exigido a busca e a construção de conhecimentos específicos capazes de atender às necessidades sociais que chegam ao Judiciário, muitas vezes veladas nos processos judiciais. 
Além do reconhecimento sobre a complexidade da realidade institucional que caracteriza o trabalho dos assistentes sociais, outro aspecto que requer uma reflexão crítica é a crescente transferência ao Poder Judiciário da responsabilidade de promover o atendimento das expressões da questão social na perspectiva da efetivação dos direitos humanos (Aguinsky, 2006). A pauperização, a precarização das relações de trabalho, o desemprego, o uso abusivo de álcool e outras substâncias psicoativas, a violência doméstica, a exploração do trabalho infantojuvenil, o preconceito social e as condições de vida dos sujeitos egressos do sistema penitenciário, assim como com os que se encontram em conflito com a lei, e a ascendente negação dos direitos constitucionais são algumas das situações vivenciadas pelos sujeitos atendidos pelo assistente social no Poder Judiciário. ${ }^{1}$ São situações diversas que requerem um conjunto de conhecimentos, habilidades e a presença da postura ética e política dos profissionais.

Portanto, diante dessa realidade entendemos que o trabalho pode se constituir num espaço privilegiado de construção de conhecimentos e processos educativos capazes de contribuir para a superação da aparência dos fenômenos com os quais os profissionais se deparam no cotidiano. Para Borgianni (2013) trata-se de fenômenos sociais e coletivos que, na maioria das vezes, surgem como individuais e atomizados, mascarando de jurídica uma questão que em essência é política e social e que, nessa esfera, também necessita ganhar resolutividade.

Os estudos que viemos realizando por meio de revisões teóricas e investigações tendo como locus o Poder Judiciário do Rio Grande do Sul,

1 No Brasil, o Poder Judiciário (que é um dos três poderes que compõem o modelo de Estado moderno junto aos Poderes Legislativo e Executivo) está regulamentado nos artigos 92 a 126 da Constituição Federal de 1988, sendo composto pelo Supremo Tribunal Federal, o Conselho Nacional de Justiça, o Superior Tribunal de Justiça, os Tribunais Regionais Federais, os Tribunais do Trabalho, os Tribunais Eleitorais, os Tribunais Militares e os Tribunais dos Estados e do Distrito Federal. Na esfera estadual, o Poder Judiciário é composto por: Tribunal de Justiça, Tribunal Militar do Estado, juízes de direito, Tribunais do Júri, Conselhos da Justiça Militar, juizados especiais, pretores e juízes de paz. 
apontam que as demandas judiciais que se colocam ao Serviço Social requerem a construção e o desenvolvimento da educação permanente, tendo a dimensão ética e política como princípio que permita a reflexão crítica sobre os processos de trabalho, suas formas de organização e sobre os conhecimentos e saberes acionados para o atendimento das demandas judiciais. Neste texto, refletimos sobre o trabalho dos assistentes sociais com demandas oriundas das Varas de Família, Infância e Juventude, Violência Doméstica e Execução Criminal.

$O$ volume crescente de processos judiciais, a complexidade da realidade social vivenciada pela população atendida, a redução das equipes técnicas diante das aposentadorias e a não reposição dos cargos vagos impõem a reinvenção do trabalho profissional. Além disto, não há como negar os reflexos da reestruturação do papel do Estado no atual momento sócio-histórico e as prioridades político-institucionais vigentes no campo da justiça e, consequentemente, as exigências postas ao Serviço Social na área.

É então, nesse contexto, que a educação permanente, enquanto proposta pedagógica de formação dos trabalhadores, surge como estratégia profissional capaz de constituir-se como uma função mediadora na proposição de respostas competentes às exigências éticas e políticas da profissão. Assim, entendemos que o espaço de trabalho se constitui num locus de aprendizagem em que os saberes são colocados à disposição para o atendimento dos sujeitos que buscam o Judiciário.

Refletir acerca do trabalho do assistente social nesse campo e a necessária disseminação de uma cultura de educação permanente entre os assistentes sociais, considerando as expressões da questão social que aparecem veladas nas demandas judiciais, é o que pretendemos neste artigo. Para tanto, primeiro fundamentamos a reflexão acerca da questão social e as demandas judiciais; segundo, nos aproximamos das particularidades do trabalho do assistente social frente às demandas judiciais, $\mathrm{e}$ na sequência apresenta-se a construção de estratégias profissionais para a educação permanente que podem incidir no atendimento da população que busca o acesso à justiça. Por fim, as considerações finais. 


\section{Demandas judiciais: a questão social velada nas naturezas processuais}

As discussões sobre as demandas judiciais são compreendidas aqui como sendo formas de ocultamento da questão social - base fundante do trabalho profissional dos assistentes sociais - e, ao mesmo tempo, expressões que se manifestam e se materializam na vida das pessoas atendidas pelo Poder Judiciário. O Serviço Social se depara com as exigências postas pelo processo de produção e reprodução do capital, com as mazelas provocadas pelas desigualdades sociais, com as violações de direitos de toda ordem, entre tantas situações que repercutem e demandam dessa instituição uma ação profissional. Neste sentido, pensar sobre as demandas judiciais exige a permanente reflexão sobre a questão social, apreendida aqui a partir da compreensão sócio-histórica de Castel (2005), pois sua análise considera as transformações históricas da sociedade capitalista, em especial a sociedade salarial, que se construiu com base no trabalho e suas proteções e que, historicamente, são atacadas e desmanteladas, como exemplo no Brasil.

Para Castel (2005), a questão social, assim nomeada pela primeira vez em 1830, reflete a constatação do distanciamento existente entre o crescimento econômico e o aumento da pobreza por um lado e uma ordem jurídico-política por outro, que reconhecia o direito do cidadão, e uma ordem econômica que os negava. É nessa época, nos primórdios da industrialização, que se tomou consciência da existência de populações que foram, "ao mesmo tempo, agentes e vítimas da Revolução Industrial” (Castel, 2005, p. 30). Ao longo do século XIX assiste-se ao amadurecimento da organização do movimento operário colocando o Estado burguês numa posição mais vigilante às reivindicações dos trabalhadores e em "estado de permanente ansiedade" (Martinelli, 2007, p. 93). A tomada de consciência operária não se refere somente ao reconhecimento das condições desumanas de vida e de trabalho da população da época, nem do pauperismo que ameaçava a ordem social e política emergente do processo de industrialização “mas, também, pela 
tomada de consciência e reação dessa classe contra essas condições" (Pereira, 2003, p. 112).

Para Castel (2005), o lugar do social deve ser visto entre a organização política e o sistema econômico, deixando clara a necessidade de construir sistemas de regulação não mercantil com o objetivo de tentar preencher esse espaço. Nesse ponto, surge o papel do Estado. Para o autor, a sociedade atual encontra-se numa bifurcação: aceitá-la inteiramente submetida às exigências do mercado ou construir uma figura do Estado social capaz de atender ao novo desafio. A primeira opção representaria o desmoronamento da sociedade salarial, enquanto a segunda representaria uma redefinição do pacto social, como um pacto de solidariedade, de trabalho, de cidadania; ou numa perspectiva marxista, considerando a presença das lutas de classes no processo de superação da lógica da sociabilidade burguesa.

Também é importante fazer referência a Netto (2001), quando afirma que a questão social é produzida compulsoriamente pelo capitalismo em seus diferentes estágios de desenvolvimento, pois é o resultado da contradição na relação capital e trabalho, da exploração da força de trabalho. As formas de enfrentamento da questão social são distintas e se configuram historicamente em consonância com o desenvolvimento do capitalismo. Cada mudança no modo de produção gera novas formas de manifestação da questão social, exigindo novas formas de enfrentamento. A partir das crescentes contradições da sociedade contemporânea, que vão desde o desemprego estrutural à obsessão da riqueza e acúmulo do capital, adensam-se os conflitos que chegam à instância judicial, sendo essa uma esfera de tentativa de resolução das mais variadas expressões da questão social. É assim, "no adensamento dessas contradições, a persistente demanda que diz da legitimação do trabalho do Serviço Social no campo jurídico" (Aguinsky, 2003, p. 85).

É importante sublinhar que o conceito de demanda é aqui entendido em sua relação com o direito significando o processo e/ou a ação judicial como demanda judicial. No sentido formal, no âmbito do Poder Judiciário, toda ação é um direito subjetivo público e abstrato independente de haver 
realmente um direito a ser tutelado. Trata-se do direito de exigir do Estado a prestação jurisdicional, a solução de uma lide ou conflito. Entretanto, seu significado também compreende a noção de luta, de reivindicação, ação de exigir, de contestar. No dicionário, ${ }^{2}$ demanda significa litígio, requerimento, pedido. Contudo, o propósito aqui é relacionar a noção de demanda judicial com necessidades sociais que são apreendidas como necessidades humanas. Para Pereira (2011, p. 20), há a possibilidade de as "classes econômicas e socialmente desfavorecidas transformarem suas necessidades em questões e incluí-las na agenda política vigente, desde que se transformem em atores sociais estrategicamente posicionados". Isto significa dizer que as

necessidades sociais só poderão se transformar em questões perturbadoras da ordem estabelecida (e definidoras de direitos, que deverão ser concretizados por políticas), se forem "problematizadas" por classes, frações de classes, organizações, grupos e, até, indivíduos, estrategicamente situados e dotados de condições políticas para incorporar estas questões na pauta das prioridades públicas. (Pereira, 2011, p. 20)

Porém, é importante que se diga que a emergência de uma questão - advinda de necessidades problematizadas - não é garantia de sua satisfação por meio de respostas públicas, pois as formas de reação se apresentam em campos de disputa e colocam em movimento conflitos de interesses no seio das políticas e espaços públicos.

\section{As demandas judiciais que se apresentam ao Serviço Social}

Considerando o que vimos até aqui, podemos dizer que as demandas que se apresentam ao Serviço Social no Judiciário se manifestam de

2 Bueno, Silveira. Minidicionário da língua portuguesa. 2. ed. São Paulo: FTD, 2007. 
diferentes maneiras, dependendo dos encaminhamentos institucionais realizados pelos operadores do sistema de justice (juízes, promotores, advogados e/ou outros profissionais). A partir dos estudos de Borba (2019) é possível observar que das demandas judiciais que chegam ao trabalho profissional no Judiciário do Rio Grande do Sul emergem três categorias, a saber: demandas de natureza processual (oriundas, na sua maioria, das varas da infância e da juventude, das varas de família e das varas criminais); demandas consolidadas e demandas emergentes.

As demandas de natureza processual se relacionam com a diversidade da vida social materializada nos processos judiciais e que caracterizam algum tipo de conflito ou negação de um direito passível de resolução legal. É comum, em comarcas no interior do Estado, juízes de diferentes varas requisitarem de um(a) mesmo(a) profissional uma intervenção técnica. Isto expressa a heterogeneidade das demandas judiciais por natureza processual que chegam a esses profissionais, tais como: na área da infância, a destituição do poder familiar, acolhimento institucional, adoção, entre outros; na área da família, guarda, tutela, interdição e outras; e na área criminal, medida protetiva de violência doméstica contra a mulher e execução de penas e medidas alternativas.

A perícia social é, historicamente, considerada uma demanda já consolidada à profissão no processo judicial e traduz a expectativa que a instituição tem do trabalho das assistentes sociais. Contudo, existem requisições "inusitadas”, como, por exemplo, a perícia social em processos de curatela. Nessas situações, podem ocorrer dificuldades profissionais em identificar o objetivo da avaliação social determinada, visto que pode haver indícios de um caráter "fiscalizatório" nessa intervenção. Ao contrário, essas avaliações devem ter a preocupação com a proteção daqueles que estão sob curatela, em que a finalidade da intervenção técnica é dada pelo profissional (Borba, 2019).

Outro aspecto marcante refere-se à violência, que é a expressão mais visível da questão social contida nos processos judiciais em todas as áreas de atuação do Serviço Social no Poder Judiciário. Observa-se que 
a violência e a opressão que fazem parte da sociedade brasileira não se restringem a ambientes específicos, mas se manifestam e se realizam no convívio social, repercutindo na organização social e familiar. Mioto (2009) destaca a violência econômica, que para Marx trata-se da violência originária, indispensável ao capital. Entretanto, a autora refere que nem sempre ela é percebida no momento em que é produzida, mas tem efeitos e se explicita nas relações, como por exemplo: na violência doméstica e contra a mulher, no feminicídio que assombra a realidade brasileira atual, nas situações de violência contra os idosos, assim como contra crianças, adolescentes e juventudes que justificam a quantidade de processos judiciais existentes.

O resultado da perícia social é o laudo social, que se sobressai como demanda institucional consolidada para o Serviço Social. Para Araújo (2000, p. 31), laudo social é o documento

elaborado pelo perito assistente social, sendo o resultado visível de sua intervenção técnica. Nele deverão estar identificadas as principais pessoas ou partes envolvidas no processo judicial, relatados os dados mais importantes coletados junto a estas partes, as impressões do profissional, sua análise e as indicações para a resolução do conflito judicial. Além de um documento profissional, ele também é um documento de prova judicial, e como tal deverá ter uma estrutura formal, delineando-se partes lógicas de categorias de dados informativos. A fim de cumprir o que pretende, deverá ser claro, objetivo e imparcial, indicando alternativas que visem subsidiar a sentença judicial.

A importância do laudo social como parte da construção legal de decisões judiciais traz ao profissional a responsabilidade de indicar alternativas de resolução da demanda judicial (Araújo, 2000). Afinal, para Aguinsky, o laudo social (2003, p. 99) "carrega emblematicamente o poder do discurso do assistente social para dentro do terreno da luta simbólica do campo jurídico entre profissionais que, dotados de competências técnicas e sociais distintas, visões de mundo diferentes, vão procurar incidir 
na decisão judicial". Na busca por revelar as necessidades sociais ocultas nas demandas judiciais, o Serviço Social se coloca no caminho inverso do caminho jurídico, uma vez que nem sempre essas demandas são compreendidas no âmbito judiciário como necessidades sociais dos sujeitos.

Assim sendo, o trabalho do assistente social é o de "superar a distância em relação ao cotidiano dos sujeitos envolvidos no conflito para nele apreender significados, subjetividades, objetividades" (Aguinsky, 2003, p. 100). Nesse sentido, refletir acerca dos conhecimentos que fundamentam a instrumentalidade do trabalho profissional no Judiciário é fundamental. Até a linguagem técnica utilizada pelos assistentes sociais, tanto oralmente quanto na escrita, esta última identificada nos pareceres e laudos técnicos, sem dúvida é uma habilidade a ser desenvolvida pelos profissionais.

Já as demandas emergentes no trabalho do assistente social se apresentam relacionadas às novas práticas institucionais. Dentre elas destacam-se: o depoimento especial, que trata da escuta de crianças e adolescentes vítimas de violência sexual em audiência judicial nos processos criminais; a justiça restaurativa, que se apresenta como política de justiça para o enfrentamento de conflitos e as práticas de mediação, constelação familiar e os encontros de preparação para adoção (Borba, 2019).

Nesse contexto, o trabalho com as varas de violência doméstica e familiar contra a mulher revela-se também como uma demanda emergente, visto que a Lei Maria da Penha (Lei n. 11.340/2006) prevê a criação de equipe técnica judicial para assessorar o juiz. Entretanto, existem situações em que esse trabalho é realizado somente por uma assistente social, o que pode dificultar e/ou evidenciar a inexistência do trabalho interdisciplinar incidindo nas condições reais de atendimento dessa população. Sobre as práticas de justiça restaurativa, mediação ${ }^{3}$ e

3 No Brasil, a mediação é vista como meio distinto de solução de conflitos. O Código de Processo Civil (Lei n. 13.105/2015) reafirma que na mediação o mediador facilita o diálogo entre as 
constelações familiares, ${ }^{4}$ vimos que essas requisições traduzem as contradições que se apresentam no espaço institucional e que o "atropelamento" cotidiano que impede a apropriação dos conhecimentos necessários para o desenvolvimento dessas intervenções é recorrente. A discussão sobre essas demandas não é nova para o Serviço Social e requer atenção no seu uso e intencionalidades, assim como uma reflexão crítica, tendo como base os fundamentos em Serviço Social. Para alguns, trata-se de práticas terapêuticas também conhecidas como "Serviço Social clínico". O conjunto CFESS/Cress (2008), em manifestação sobre o tema, apresenta informações a respeito do objeto, os objetivos e metodologias utilizadas, assim como aborda a questão em relação ao projeto profissional. ${ }^{5}$

No espectro das demandas emergentes, o trabalho em rede desponta como importante estratégia profissional de interlocução com as diferentes políticas sociais públicas. Por isso a importância do reconhecimento dessa articulação a ser realizada pelos assistentes sociais do Poder Judiciário com as políticas sociais, embora essa seja uma prerrogativa de todos os operadores de direito. O Serviço Social tem como um de seus principais espaços sócio-ocupacionais o âmbito das políticas sociais (seja na educação, na assistência social, na saúde, na previdência social, na habitação, entre outras) e, mesmo não sendo uma atribuição privativa, é preciso atenção às competências do trabalho profissional que muitas

pessoas para que elas mesmas proponham soluções (art. 165, §3º). A outra diferenciação está pautada no tipo de conflito. Para conflitos objetivos, mais superficiais, nos quais não existe relacionamento duradouro entre os envolvidos, aconselha-se o uso da conciliação; para conflitos subjetivos, nos quais exista relação entre os envolvidos ou desejo de que tal relacionamento perdure, indica-se a mediação. Muitas vezes, somente durante o procedimento é identificado o meio mais adequado. Disponível em: http://www.cnj.jus.br/programas-e-acoes/conciliacao-e-mediacao-portal-da-conciliacao/perguntas-frequentes/85619-qual-a-diferenca-entre-conciliacao-e-mediacao. Acesso em: 10 set. 2018.

4 Trata-se de uma técnica psicoterapêutica criada pelo alemão Bert Hellinger, usada no Poder Judiciário, pelas varas de família, de pelo menos dezesseis estados, que se mostra eficaz quando o assunto é disputa de guarda de crianças, alienação parental, inventários e pensão alimentícia. Disponível em: http://www.cnj.jus.br/noticias/cnj/86659-constelacao-pacifica-conflitos-de-familia-no-judiciario. Acesso em: 10 mar. 2018.

5 Ver CFESS, 2008. 
vezes diz respeito ao coletivo que atua nas diferentes instâncias, e não somente a um profissional.

O trabalho em rede realizado com a participação do assistente social judiciário pode incidir no processo de judicialização da questão social e no fortalecimento das políticas públicas e, fundamentalmente, no atendimento das necessidades humanas dos sujeitos de direitos. No âmbito das estratégias profissionais, a reflexão sobre a intersetorialidade se justifica quando se observa a configuração fragmentada e desarticulada das políticas públicas no Brasil, a qual obstaculiza o atendimento das necessidades da população em sua integralidade. Assim, a intersetorialidade é um pilar estruturante do princípio da integralidade das ações de algumas políticas públicas, colocando-se como um dos maiores desafios aos trabalhadores da área (Nogueira e Mioto, 2006).

O lugar estratégico do Serviço Social no Judiciário requer dos assistentes sociais uma intervenção técnica-operativa que articule com as políticas sociais, principalmente com aqueles profissionais que trabalham no atendimento da população que enfrenta cotidianamente a desarticulação dos serviços. A precarização e o desmonte das políticas públicas, principalmente no âmbito da Seguridade Social, impactam direto no aumento das demandas judiciais, diante da negação do acesso aos direitos sociais, principalmente na área da infância e da juventude, com a instauração crescente de processos judiciais.

\section{Apontamentos para uma agenda de educação permanente}

Antes de avançarmos na discussão das temáticas que podem compor uma agenda de educação permanente para o trabalho dos assistentes sociais no Poder Judiciário, é preciso situar os subsídios que fundamentam a compreensão sobre a importância dos processos educativos vivenciados no trabalho. Temos como ponto de partida que o trabalho é um espaço privilegiado de aprendizagem e construção de conhecimentos. O Serviço 
Social ocupa um lugar estratégico no atendimento das necessidades sociais que chegam ao Poder Judiciário e, por isso, a educação permanente desponta como uma dimensão formativa para os assistentes sociais, assim como para os demais profissionais (Fernandes, 2016).

A educação entendida em sentido amplo, não se restringindo aos níveis de ensino ou sistemas escolares, mas à educação como processo social vital da existência dos sujeitos. Ou seja, aquilo que caracteriza a sua especificidade de ser social, a saber, a capacidade de conhecer, de ter ciência do real e de, portanto, transformá-lo de forma consciente (Mészáros, 2008). Para Mészáros (2008), a automudança consciente é a maneira pela qual os indivíduos poderão, numa nova ordem social, tomar decisões conscientes sobre a forma de gestão de sua própria vida, incluindo aquela vivida no trabalho como estratégia de sobrevivência nos processos de exploração do capital.

Esse controle consciente dos processos sociais, segundo Mészáros (2008), converte-se na superação da forma alienada de mediação dos homens entre si, tornando-se uma mediação consciente, uma efetiva automediação. Busca-se uma vida determinada pelas necessidades humanas efetivas, e não pelas necessidades fetichizadas e artificiais criadas no âmbito do capital. Assim, a educação deixa de ser um momento específico da vida, com fins utilitários determinados, para ser a própria vida de todos os sujeitos. Mészáros (2008) afirma que isso é uma necessidade urgente, pois envolve a sobrevivência da humanidade, considerando o atual nível de desenvolvimento da sociedade do capital.

No Poder Judiciário não são poucas as situações que requerem dos profissionais um conjunto de conhecimentos para o atendimento das necessidades postas pelos sujeitos de direitos. Isso significa considerar as situações de trabalho e as necessidades, que emergem nesse contexto como indicadores dos saberes necessários a serem apreendidos para o atendimento e/ou a efetivação dos direitos sociais. A organização do trabalho nesse campo segue ritos rígidos e hierárquicos, onde o juiz centraliza o poder de decisão diante dos conflitos com base em pressupostos formais do Estado de direito. 
A aparência do direito (e do Poder Judiciário) como algo acima dos interesses das classes sociais, supostamente capaz de captar as necessidades sociais como um todo, cumpre um papel fundamental na construção de um véu que encobre as relações de desigualdade social que não podem aparecer enquanto tal. A fim de superar uma visão simplista e ilusória do real, o assistente social comprometido com o seu projeto ético-político profissional é impelido a construir saberes, competências e habilidades no e para o exercício profissional.

Frente aos limites e desafios postos no cotidiano, alguns dispositivos são importantes para o desenvolvimento da cultura da educação permanente no trabalho. Para além da existência de diretrizes políticas para a institucionalização de processos de educação permanente no âmbito das políticas públicas, como exemplo na Saúde (Brasil, 2009) e na Assistência Social (Brasil, 2013), Fernandes (2016) reconhece que o desejo do profissional em envolver-se em processos formativos a partir das demandas que surgem no trabalho é imprescindível. $O$ que se constitui numa escolha individual, mas também coletiva, visto que compromete e responsabiliza os envolvidos com os resultados da ação. Por isso a importância da iniciativa dos trabalhadores advinda desse desejo por meio da qual se poderia dar mais sentido às experiências vivenciadas no trabalho, aos saberes já existentes e "a um serviço prestado que foi planejado, que tem uma intencionalidade e que só se constrói por meio da problematização de uma demanda ou situação posta" (Fernandes, 2016, p. 79).

Com base nos fundamentos trazidos é que temos a convicção da importância e da possibilidade de construção coletiva de uma agenda de educação permanente para o trabalho dos assistentes sociais no Poder Judiciário, principalmente em tempos de manifestações conservadoras e descoladas dos fundamentos da profissão cujas bases teórico-metodológica, técnico-operativa e ético-política preconizadas pelo Serviço Social devem ser acionadas e protegidas com zelo pela categoria. Isso posto, é no âmbito sociojurídico que constatamos a necessidade de construção de "parâmetros técnicos mínimos para o trabalho dos assistentes sociais no Poder Judiciário nas áreas da infância e juventude, família e crime". 
emergindo como importante estratégia para a formação desses trabalhadores (Borba, 2019).

Quando tratamos de processos de educação permanente é preciso reconhecer que a predisposição ética e política para buscar conhecimentos e utilizá-los no trabalho, assim como a clareza das mediações necessárias são condições para essas experiências formativas. Embora seja importante a existência e a construção na gestão do trabalho - no Poder Judiciário - das prerrogativas institucionais para o fomento das aprendizagens considerando as demandas postas, é preciso que os trabalhadores reconheçam os conhecimentos que devem acionar a partir das situações trazidas pelos sujeitos que atendem. Borba (2019) aponta que entre os conhecimentos acionados e/ou necessários para o trabalho dos assistentes sociais no Poder Judiciário estão as legislações vigentes nas áreas da infância e da juventude, da família e do crime, assim como sobre os marcos regulatórios das políticas sociais. ${ }^{6}$ Em um cenário de desmonte das legislações vigentes, o Serviço Social no Judiciário, como classe trabalhadora, se coloca numa posição ética e política de resistência em fazer valer esses conhecimentos na perspectiva da efetivação e ampliação dos direitos sociais.

A ideia da construção de parâmetros mínimos de atuação nas áreas da infância e juventude, família e crime versa sobre temas específicos que consideram as realidades dos espaços ocupacionais, as condições de vida da população, entre outros aspectos que são definidos pelo conjunto de demandas postas e, ainda, pelas condições de trabalho e pelas necessidades de os trabalhadores vivenciarem aprendizagens significativas.

6 Estatuto da Criança e do Adolescente (Lei n. 8.069/1990) e Lei n. 12.010/2009. Código de Processo Civil (Lei n. 13.105/2015); Lei da Alienação Parental (Lei n. 12.318/2010); Estatuto do Idoso (Lei n. 10.741/2003); Lei de Execução Penal (Lei n. 7.210/1984); Lei Violência Doméstica e Familiar contra a Mulher (Lei n. 11.340/2006); Lei n. 9.099/1995, que regulamenta os juizados especiais criminais; Lei n. 11.343/2006, que regulamenta a política antidrogas; Lei n. 10.826/2003, que regulamenta o uso de arma; Constituição Federal de 1988 (art. 5º, entre outros); marcos regulatórios: Sistema Único de Saúde (Lei n. 8.080/1990), Sistema Único de Assistência Social (Lei n. 12.435/2011). 
Na infância e juventude o tema da adoção tem sido considerado uma prioridade institucional demandada ao trabalho das assistentes sociais, pois a adoção tardia, os encontros com adotantes e as devoluções de adotados são assuntos a serem aprofundados (Borba, 2019). A devolução de crianças e adolescentes adotados também é uma preocupação profissional, visto a incidência desses casos. A aproximação de adotantes e crianças e adolescentes aptos para adoção também requer reflexão sobre o planejamento dessa ação, envolvendo a definição de objetivos e finalidades para essa prática. Na área da família, o desafio é o de desvelar as expressões da questão social presentes nos processos judiciais, visto a dificuldade de identificação do objeto da avaliação social, assim como da própria finalidade do trabalho do assistente social na área da família. Na área criminal, especificamente na execução de penas e medidas alternativas, percebe-se a necessidade de aprofundamento e socialização da legislação existente que regulamenta as alternativas penais no país, assim como as práticas existentes nas diferentes comarcas de cada estado.

Por fim, não podemos deixar de destacar a importância da visita domiciliar como recurso utilizado e constantemente solicitado ao assistente social judiciário. Isto nos faz refletir sobre a histórica preocupação da profissão e a exigência social na área com esse instrumento de trabalho, em detrimento de outros, como o planejamento e a pesquisa. É preciso compreender a visita domiciliar no trabalho profissional como sendo uma forma de conhecer os modos e condições de vida dos sujeitos de direitos nas suas moradias, nos seus territórios, nos seus cotidianos, tendo o diálogo, o respeito e a construção de vínculos, princípios para superação do caráter fiscalizatório que pode carregar esse instrumental. Trata-se de ter clareza sobre a finalidade e a situação a ser medida no trabalho profissional. Para Closs e Sherer (2016, p. 3), esse instrumento é balizado por "uma dimensão investigativa que possibilita apreender os processos sociais singulares em conexão com a dinâmica societária, juntamente com uma postura ético-política comprometida com o atendimento das necessidades sociais e com o respeito da liberdade e da autonomia”. 
Os conhecimentos e instrumentais utilizados pelos assistentes sociais e a reflexão acerca dos preceitos éticos e políticos que envolvem esse trabalho também são temas a compor os parâmetros mínimos de atuação profissional não como algo fechado, mas como um guia orientador de conteúdos que contribuam com as aprendizagens significativas tão necessárias para o trabalho do Serviço Social no Poder Judiciário nas diferentes áreas de atuação (infância, família e crime).

\section{Considerações finais}

O Serviço Social brasileiro vem se consolidando como uma profissão marcada por uma direção social crítica e democrática, modificando-se no contexto das relações sócio-históricas da sociedade, as quais são permeadas pela disputa de projetos societários e das classes sociais nas respostas às múltiplas expressões da questão social. Pensar o Serviço Social no Poder Judiciário - em um cenário de rearticulação de forças conservadoras que buscam instaurar uma agenda neoliberal no campo econômico e social, com graves consequências no campo dos direitos e políticas sociais conquistados historicamente - implica a reafirmação de compromissos. A postura ético-política e o aprofundamento dos fundamentos para o trabalho profissional são necessários para a compreensão do movimento contraditório da realidade e para a construção de estratégias de resistência, de ampliação da participação da população usuária e afirmação da cidadania é um caminho.

A crescente judicialização da questão social na busca pela garantia da efetivação de direitos sociais é um desafio para a construção de estratégias coletivas de ação que envolve, dialeticamente e de maneira tênue, transitar da perspectiva do controle para a da emancipação. A construção de mediações e acúmulos no que tange à dimensão técnico-operativa, especialmente a partir de uma perspectiva dialético-crítica, pode superar concepções praticistas e aproximar a dimensão teleológica do trabalho na articulação do instrumental, trazendo os fundamentos do Serviço Social como base para a formação profissional no âmbito do trabalho. 
Contudo, a institucionalização de uma cultura de educação permanente no e do trabalho dos assistentes sociais no Poder Judiciário se constitui um desafio. Para tanto, o envolvimento dos trabalhadores é uma alternativa para a construção coletiva de uma agenda de educação permanente para o trabalho profissional no ambiente sociojurídico que nos mobilizou para esta escrita.

\section{Referências}

AGUINSKY, Beatriz G. Eticidades discursivas do Serviço Social no campo jurídico: no claroescuro da legalidade da moral. Tese (Doutorado) — PPG/FSS-PUCRS, Porto Alegre, 2003.

; HUFF DE ALENCASTRO, Ecleria. Judicialização da questão social: rebatimentos no processo de trabalho dos assistentes sociais no Poder Judiciário. Katalysis, Florianópolis. jan.-jun. 2006.

ARAÚjo, R. de. Perícia social judiciária: o modelo de Porto Alegre. Cadernos de Serviço Social, Campinas, n. 16, 2000.

BORBA, Mariana P. A construção de uma agenda de educação permanente no trabalho dos assistentes sociais do Poder Judiciário do Rio Grande do Sul. Dissertação (Mestrado) Programa de Pós-Graduação em Política Social e Serviço Social, Instituto de Psicologia, UFRGS, Porto Alegre, 2019.

BORGIANNI, Elisabete. Para entender o Serviço Social na área sociojurídica. Serviço Social \& Sociedade, São Paulo, n. 115, p. 442-470, 2013.

BRASIL. Ministério do Desenvolvimento Social e Combate à Fome. Conselho Nacional de Assistência Social. Política Nacional de Educação Permanente da Política Assistência Social, 2013. Disponível em: http://www.mds.gov.br/webarquivos/publicacao/assistencia_social/ Normativas/Politica-nacional-de-Educacao-permanente.pdf. Acesso em: 4 maio 2017.

Ministério da Saúde. Política Nacional de Educação Permanente em Saúde, 2009. Disponível em: <http://portal.anvisa.gov.br/documents/33856/396770/Pol\%C3\%ADtic a+Nacional+de+Educa\%C3\%A7\%C3\%A30+Permanente+em+Sa\%C3\%BAde/c92db117e170-45e7-9984-8a7cdb111faa>. Acesso em: 4 maio 2017.

. LEI MARIA DA PENHA. Lei n. 11.340, de 7 de agosto de 2006. Disponível em: http://www.planalto.gov.br/ccivil 03/ato2004-2006/2006/lei/111340.htm. Acesso em: 3 maio 2017.

CASTEL, Robert. As metamorfoses da questão social: uma crônica do salário. Rio de Janeiro: Vozes, 2005. 
CLOSS, T. T.; SHERER, G. A visita domiciliar no trabalho do assistente social: desafios em tempos de crise e conservadorismo. Anais: III Seminário Regional de Políticas Públicas, Intersetorialidade e Família. Porto Alegre, 2016. Disponível em: http://ebooks.pucrs.br/ edipucrs/anais/serpinf/2016/assets/14.pdf. Acesso em: 20 mar. 2018.

CONSELHO FEDERAL DE SERVIÇO SOCIAL - CFESS. Práticas Terapêuticas no âmbito do Serviço Social. Subsídios para aprofundamento do estudo. Brasília, 2008.

Código de ética profissional. Brasília, 1993.

FERNANDES, Rosa Maria Castilhos. Educação permanente e políticas sociais. Campinas: Papel Social, 2016.

IAMAMOTO. Marilda Villela. Serviço Social em tempo de capital fetiche: capital financeiro, trabalho e questão social. 9. ed. São Paulo: Cortez, 2015.

MARTINELLI, Maria Lúcia. Identidade e alienação. 11. ed. São Paulo: Cortez, 2007.

MÉSZÁROS, István. A educação para além do capital. 2. ed. São Paulo: Boitempo, 2008.

MIOTO, Regina. C. T. Família e políticas sociais. In: BOSCHETTI, Ivanete et al. (org.). Política social no capitalismo: tendências contemporâneas. 2. ed. São Paulo: Cortez, 2009. p. 130-148.

NETTO, J. P. Cinco notas a propósito da questão social. Temporalis, Brasília, ano 2, n. 3, jan.-jul. 2001.

PEREIRA, Potyara A. P. Necessidades humanas: subsidios à crítica dos mínimos sociais. 6. ed. São Paulo: Cortez, 2011.

Perspectivas teóricas sobre a questão social no Serviço Social. Temporalis, Brasília, ano IV, jan.-jun. 2003.

\section{Sobre as autoras}

Mariana Pires Borba - Assistente social, mestre em Política Social e Serviço Social.

E-mail: asjmarianapb@gmail.com

Rosa Maria Castilhos Fernandes - Doutora em Serviço Social e professora de Serviço Social.

E-mail:rmariacf@uol.com.br 